\title{
PROTEÇÃO A AUTODETERMINAÇÃO SEXUAL NO DIREITO PENAL BRASILEIRO E ALEMÃO: OS MODELOS DE CONSETIMENTO COMO FORMA DE DELIMITAÇÃO DA RESPONSABILIDADE PENAL
} PROTECTION TO SEXUAL SELF-DETERMINATION IN BRAZILIAN AND GERMAN CRIMINAL LAW: MODELS OF CONSENT AS A FORM OF DELIMITATION OF PENAL RESPONSIBILITY

Renato Kramer ${ }^{1}$

Humboldt-Universität Berlin - DE

\section{Resumo}

A liberdade da autodeterminação sexual é um bem jurídico tutelado tanto no direito penal brasileiro quanto no alemão. Esse bem jurídico recebeu atualmente uma atenção especial pelo legislador alemão ao acrescentar alguns elementos ao seu tipo penal. Essa alteração deveu-se a uma discrepância havida anteriormente entre os crimes patrimoniais e sexuais, já que não havia a figura do estelionato sexual. Portanto, atendendo à convenção de Istambul da qual a Alemanha é signatária, o legislador resolveu, então, alterar o $§ 177$ do StGB. Da mesma forma, o legislador brasileiro, no ano de 2009, deu uma atenção especial a esse bem jurídico. Ambas legislações pretendem proteger o mesmo bem jurídico, porém adotando dois modelos distintos. Esses modelos dão respostas desproporcionais, pois um deles acaba criminalizando excessivamente e outro descriminalizando. No entanto, um desses modelos mostra-se mais adequado, já que mais garantista, sugerindo inclusive uma alteração por parte do legislador brasileiro. A investigação da liberdade da autodeterminação sexual e os seus modelos correspondentes são o objeto da presente pesquisa.

Palavras-chave

Liberdade da autodeterminação sexual. Modelos de consentimento. Ciência penal.

${ }^{1}$ Doutorando em Direito pela Humboldt-Universität, em Berlim. 


\section{Abstract}

The freedom of sexual self-determination is a legal right protected in both Brazilian and German criminal law. This legal right has now received special attention by the German legislature in adding some elements to its criminal type. This change was due to a previous discrepancy between patrimonial and sexual crimes, since there was no figure of sexual fraud. Therefore, in view of the Istanbul Convention to which Germany is a signatory, the legislature then decided to amend Paragraph 177 of the Criminal Code. In the same way, the Brazilian legislator, in 2009, gave special attention to this legal good. Both laws seek to protect the same legal good, but adopting two different models. These models give disproportionate responses, because one ends up criminalizing excessively and the other decriminalizing. However, one of these models appears to be more appropriate, since more guarantor, suggesting even an amendment by the Brazilian legislature. The investigation of the freedom of sexual self-determination and its corresponding models are the object of the present research.

\section{Keywords}

Freedom from sexual self-determination. Models of consent. Criminal science.

\section{Zusammenfassung}

Die Freiheit der sexuellen Selbstbestimmung ist ein Rechtsgut, das sowohl durch das brasilianische Strafrecht als auch durch das deutsche Strafrecht geschützt ist. Der deutsche Gesetzgeber hat dieses Rechtsgut speziell analysiert, zumal manche Merkmale im Tatbestand eingeführt wurden. Diese Änderung geschah, weil es eine Diskrepanz zwischen dem Vermögensverbrechen und Sexualverbrechen gab, das heißt, wir hatten keinen sexuellen Betrug. Damit war Deutschland verpflichtet, aufgrund der Istanbul-Konvention, den $\mathcal{S} 177$ StGB zu ändern. Ebenfalls hat der brasilianische Gesetzgeber das Gleiche im Jahr 2009 gemacht. Beide Gesetze haben vor, das selbe Rechtsgut zu schützen, aber sie nahmen verschiedene Modelle, die unverhältnismäßigen Antworten geben, an. Ein Modell kriminalisiert zu viel und das andere nichts. Allerdings ist ein dieser Modelle das Beste, weil es adäquater und sicherer ist und deswegen muss der nationale Gesetzgeber das Gesetz ändern. Der Gegenstand dieser Untersuchung ist die Freiheit der sexuellen Selbstbestimmung und ihre entsprechenden Modelle.

\section{Schlüsselwörter}

Freiheit der sexuellen Selbstbestimmung. Zustimmungsmodelle. Strafrechtliche Wissenschaft. 


\section{Introdução}

A autonomia sexual vem passando por um momento de revalorização nas sociedades atuais.

A europeização e a internacionalização do Direito penal abrangem também há muito tempo o Direito penal sexual. Tanto a nível do conselho europeu quanto a nível do direito internacional encontram-se variadas regras, as quais contêm diretrizes para o legislador alemão no sentido de concretizar delitos contra a autodeterminação sexual. ${ }^{2}$

A autodeterminação sexual pode ser entendida em um sentido amplo. Conceitualmente são previstos não apenas tipos penais que dizem respeito à restrição da liberdade e à violação sexual, como também aqueles tipos penais que objetivam proteger tão somente perante perturbações sexuais. A constituição da vontade do afetado e a proteção do jovem no sentido de um desenvolvimento livre, são também, consequentemente, aspectos de uma autodeterminação sexual. $^{3}$

No que diz respeita a ela - autodeterminação sexual -, o código penal brasileiro sofreu uma modificação no ano de 2009, passando o artigo 215 a ter uma nova redação ${ }^{4}$. No que diz respeito à redação

2 BLUME, Lara; WEGNER, Kilian. Reform des §177 StGB? - Zur Vereinbarkeit des deutschen Sexualstrafrechts mit Art. 36 der Instanbul Konvention. In: Online Zeitschrift für Höchstrichterliche Rechtsprechung zum Strafrecht, 2014, p. 357. ${ }^{3}$ STICK, Brigitte. Zweierlei Recht für zweierlei Geschlecht: Wertungswidersprüche im Geschlechterverhältnis am Beispiel des Sexualstrafrechts. In: ZStW 103 (1991) Heft 1, Tübingen, p. 50.

4 "Ter conjunção carnal ou praticar outro ato libidinoso com alguém, mediante fraude ou outro meio que impeça ou dificulte a livre manifestação de vontade da vítima: (...)”. 
antiga constata-se o seguinte cenário: o crime só podia ser praticado contra uma mulher - e, consequentemente, apenas mediante conjunção carnal (1) e mediante fraude (2) ${ }^{5}$. Agora temos o seguinte cenário: o crime pode ser também praticado contra um homem, pois o tipo penal prevê a expressão "ou praticar outro ato libidinoso com alguém"; além disso, acrescentou-se a expressão "ou outro meio que impeça ou dificulte a livre manifestação de vontade da vítima", constatando-se a ampliação do tipo penal por meio da interpretação analógica.

Na seara do Direito alemão o código penal sofreu uma alteração no ano de 2016, passando o $\S 177$ a ter uma nova redação ${ }^{6}$. O texto anterior previa a prática do crime sexual mediante violência ou ameaça ou a utilização de uma situação de vulnerabilidade. Com a nova redação acrescentou-se a expressão contra a vontade reconhecível de uma outra pessoa ("gegen den erkennbaren Willen einer anderen Person'). Isso significa que é possível através dessa expressão a prática do crime sexual mediante engano. Ou seja, a partir do momento em que o agente engana a vítima para que com ele pratique atos sexuais estar-se-á diante de um vício de vontade, daí a previsão da expressão contra a vontade reconhecível de uma outra pessoa.

5 "Ter conjunção carnal com mulher, mediante fraude: (...)".

${ }^{6}$ (1) Wer gegen den erkennbaren Willen einer anderen Person sexuelle Handlungen an dieser Person vornimmt oder von ihr vornehmen lässt oder diese Person zur Vornahme oder Duldung sexueller Handlungen an oder von einem Dritten bestimmt, wird mit Freiheitsstrafe von sechs Monaten bis zu fünf Jahren bestraft.

(2) Ebenso wird bestraft, wer sexuelle Handlungen an einer anderen Person vornimmt oder von ihr vornehmen lässt oder diese Person zur Vornahme oder Duldung sexueller Handlungen an oder von einem Dritten bestimmt, wenn

1. der Täter ausnutzt, dass die Person nicht in der Lage ist, einen entgegenstehenden Willen zu bilden oder zu äußern, (...)”. A citação do parágrafo restante é dispensável para o objeto deste trabalho. 
Essa modificação deveu-se à convenção de Istambul da qual a Alemanha é signatária. O dispositivo legal dessa convenção obriga aos Estados signatários a punir todos os atos sexuais contra a vontade de uma pessoa assim como a conceder um processo penal efetivo. ${ }^{7} \mathrm{Com}$ essa reforma buscou-se ampliar o tipo penal, ou seja, objetivou-se não apenas prever atos que, mediante violência ou grave ameaça, atentassem contra a autodeterminação sexual da pessoa, como também aqueles que fossem praticados mediante erro.

A discussão partiu do seguinte ponto: ora, o código penal alemão prevê o crime de roubo e estelionato cujo bem jurídico tutelado é o patrimônio. De um lado, o roubo pode ser praticado mediante violência ou grave ameaça, de outro, o estelionato mediante a indução a erro. Já no âmbito dos crimes sexuais o código penal germânico prevê o estupro - praticado mediante violência ou grave ameaça - cujo bem jurídico tutelado é a liberdade da autodeterminação sexual. Até o ano de 2016 - ano da reforma - não havia o crime de violação sexual mediante fraude e, por consequência, não havia uma simetria com os crimes patrimoniais.

Portanto, constata-se, à primeira vista, uma inconsistência no âmbito de proteção do bem jurídico penal. O Direito penal alemão estaria protegendo melhor um bem jurídico de menor importância e de forma mais abrangente do que o altamente pessoal (e de valor de proteção alto) bem jurídico autodeterminação sexual. ${ }^{8}$

${ }^{7}$ HÖRNLE, Tatjana. Menschenrechtliche Verpflichtungen aus der InstanbulKonvention: Ein Gutachten zur Reform des $§ 177$ StGB, Berlin, 2015, p. 5.

${ }^{8}$ EL-GHAZY, Mohamad. Der neue Straftatbestand des sexuellen Übergriffs nach $\S$ 177 Abs. 1 StGB n.F. In: ZIS 3/2017, p. 159. Lackner e Kühl aduzem que o bem jurídico tutelado no § 177 do StGB é a liberdade da autodeterminação sexual (Lackner; Kühl. Strafgesetzbuch. Kommentar: 29. Auflage, C.H.BECK, München, 2018, p. 980). Assim também WOLTERS, Gereon, In: SK-StGB: Systematischer 
Após a modificação da redação legal, a doutrina alemã iniciou uma discussão intensa a respeito de qual modelo de consentimento havia sido adotado e do alcance do tipo penal.

\section{MODELOS DE CONSENTIMENTO: „NUR JA HEIßT JA“ “ E „NEIN HEIßT NEIN“}

A intromissão sexual não exige, segundo a sua ideia, a superação de uma vontade contrária mediante uma coação, mas sim a implementação do assim chamado modelo Nein heißt Nein. O centro da atenção deste dispositivo encontra-se na reconstrução da comunicação e do contexto da relação sexual. Pelo fato de não raro as relações sexuais serem formadas de forma ambivalente, exige-se do parceiro a obrigatoriedade de comunicar a sua autodeterminação. ${ }^{9}$

Segundo a legislação anterior era apenas punível quem tinha superado a autonomia da vítima mediante violência, ameaça ou a utilização de uma situação de vulnerabilidade. A partir de agora, o § 177 do StGB prevê todo ato sexual, o qual seja praticado "contra a vontade reconhecível" de outrem. ${ }^{10}$ Portanto, enquanto que o $\S 177$ Abs. 1 pressupunha que a vítima tinha que ser forçada a ter relações de cunho sexual, a partir de agora necessita-se apenas que o agente

Kommentar zum Strafgesetzbuch: Band IV, § 174-241a StGB, 9. Auflage, Köln, p. 77.

9 JOECKS, Wolfgang; Miebach, Klaus. Münchener Kommentar zum Strafgesetzbuch. Band 3: § 80-184j, C.H.BECK, 2017, München, p. 1488.

${ }^{10}$ HOVEN, Elisa; WEIGEND, Thomas. Op. cit., p. 156. Assim também EL-GHAZY, Mohamad. Op. cit., p. 157 e WALTER, Tonio. Feministische Kriminalpolitik? In: ZSTW;129(2):492-512, 2017, p. 507. 
pratique o ato contra a vontade reconhecível dela (Nein-heißt-NeinPrinzip). ${ }^{11}$

A mudança de paradigma tem como base a ampliação do tipo penal nas intromissões sexuais sem o caráter coercitivo. $\mathrm{O} \S 177$ do StGB baseia-se na ideia de que a proteção penal da autodeterminação sexual deveria conter os requisitos físicos e psíquicos para a capacidade, no sentido de a própria vítima poder decidir se deseja ou não ser encorajada agora, aqui e por esta pessoa a um acontecimento de cunho sexual. ${ }^{12}$

Por seu turno, o modelo do Só Sim é Sim determina que qualquer conduta que não se acoberte da anuência expressa da pessoa representa uma lesão ao referido bem jurídico. Levando-o às últimas consequências, qualquer mínima distorção da percepção de realidade seria suficiente para a invalidação da vontade, abrindo margem para uma criminalização excessiva. Esse modelo é adotado pelo direito inglês ${ }^{13}$ e pelo modelo brasileiro ${ }^{14}$, a título de exemplo.

Enquanto que no modelo do Direito alemão pressupõe-se a comunicação de uma vontade contrária, no modelo do Nur Ja heißt Ja conduz-se já a uma penalização a rejeição interna do contato sexual (até onde o agente conhecia ou tinha que ter conhecido). ${ }^{15}$ Exemplificando: caso um tatuador seja contratado para tatuar as

${ }^{11}$ WOLTERS, Gereon, In: SK-StGB: Systematischer Kommentar zum Strafgesetzbuch: Band IV, § 174-241a StGB, 9. Auflage, Köln, p. 77.

${ }^{12}$ HOVEN, Elisa; WEIGEND, Thomas. Op. cit., p. 156.

${ }^{13}$ Sec. 1 SOA: "A person (A) commits an offence if (a) he intentionally penetrates the vagina, anus or mouth of another person (B) with his penis, (b) $B$ does not consent to the penetration, and (c) A does not reasonably believe that $B$ consents". 14 Artigo 2015: "Ter conjunção carnal ou praticar outro ato libidinoso com alguém, mediante fraude ou outro meio que impeça ou dificulte a livre manifestação de vontade da vítima: (...)”.

${ }^{15}$ HOVEN, Elisa; WEIGEND, Thomas. Op. cit. p.157. 
nádegas da vítima, mas aproveitando-se da situação introduz o seu pênis no ânus dela, sem que esta demonstre, verbalmente ou não verbalmente, a sua resistência, já estaria caracterizado o crime sexual. Portanto, faz-se necessário para que não ocorra o crime, a comunicação concreta por parte da vítima.

\section{ANÁLISE DE GRUPO DE CASOS CONFORME O MODELO DE CONSENTIMENTO BRASILEIRO E ALEMÃO ${ }^{16}$}

- $\quad$ Engano sobre a natureza do ato sexual: um médico apalpa sexualmente uma paciente que anuiu apenas com uma consulta ginecológica ${ }^{17}$;

Engano sobre a identidade do autor: o agente engana a vítima sobre a sua identidade. Ele finge ser uma pessoa com quem a vítima é acostumada a fazer relações sexuais ${ }^{18}$.

Engano sobre o estado corporal do autor: aqui o agente afirma ou cala-se sobre o seu próprio estado corporal, o qual é habitualmente significativo no que diz respeito ao consentimento do parceiro sexual. O agente engana a vítima, por exemplo, sobre o seu sexo biológico ${ }^{19}$, cala-se sobre uma doença sexual (como, por exemplo, uma infecção por meio do vírus HIV $)^{20}$ ou alega mentirosamente de ter

${ }^{16}$ Para tanto nos valeremos da classificação utilizada por Hoven e Weigend, em: Zur Strafbarkeit von Täuschungen im Sexualstrafrecht. In: KriPoZ, 3, 2018, p. 157-158. ${ }^{17}$ HOVEN, Elisa; WEIGEND, Thomas. Op. cit. p.157.

${ }^{18}$ Idem, ibidem, p. 157.

${ }^{19}$ R v McNally [2013] EWCA Crim 1051; [2014] Q.B. 593 (CA (CrimDiv)).

${ }^{20}$ R v Dica [2004] EWCA Crim 1103; R v Konzani [2005] EWCA Crim 706. 
excluído a possibilidade de ter filhos (por exemplo: mediante esterilização ou a ingestão de contraceptivos) ${ }^{21}$.

Engano sobre outras circunstâncias, como, por exemplo, características, motivos e intenções do autor: o agente engana sobre circunstâncias internas e externas, das quais faz a vítima dependente para a prática de atos sexuais. Informações falsas sobre a renda ou a profissão (o agente se passa por milionário) podem ser levadas em consideração, assim como sobre o status de relacionamento (o agente não fala que é casado). São levadas em consideração ainda informações falsas sobre suas verdadeiras intenções (o agente alega mentirosamente em querer casar-se com a vítima) ou sobre a sua prontidão em pagar para a obtenção de atos sexuais (o cliente não pretende pagar o valor acordado) ${ }^{22}$.

Para que os enganos perpetrados pelo parceiro sexual possam ser puníveis por causa de uma intromissão sexual, depende de como é entendida a característica do ato contra a vontade reconhecível contida no $§ 177$ Abs. 1 StGB ${ }^{23}$.

Essa expressão não deve ser analisada sob o ponto de vista da vítima, mas sim do agente. Caso consideremos o contrário, então todos os grupos de casos acima elencados seriam objeto de punição pelo direito penal alemão, no que não parece ter sido a intenção do legislador. ${ }^{24}$

${ }^{21}$ HOVEN, Elisa; WEIGEND, Thomas. Op. cit., p.158.

${ }^{22}$ Idem, ibidem, p. 158.

${ }^{23}$ Idem, ibidem, p. 158.

24 "É possível sob a visão de um terceiro objetivo analisar se a vontade contrária é reconhecível ou não. Para este terceiro a vontade é reconhecível quando a vítima se manifesta expressamente (verbalmente) ou traz à tona algo que seja possível de concluir (por exemplo: mediante choro ou resistência a um ato sexual)" (Beschlussempfehlung und Bericht des Ausschusses für Recht und 
Além disso, pensamento diverso iria contra a sistemática da lei, haja vista que tornaria o $\S 177$ Abs. 2 desnecessário, pois tal dispositivo prevê situações, nas quais, a vítima no caso concreto, não pode formar ou manifestar a sua vontade contrária. ${ }^{25}$

E de se concluir que em todos os quatro grupos de casos acima delineados não há que se falar em enganos, pelo fato de não preencherem os requisitos de uma intromissão sexual, conforme o direito vigente. Ainda um último argumento seria o seguinte: alcançando o agente mediante manipulação o consentimento do parceiro sexual, evitar-se-ia com isso a formação de uma vontade contrária ${ }^{26}$.

Em que pese esses casos não alcançarem o tipo do § 177 podese amoldá-los em outros tipos penais presentes no código penal alemão. Ao primeiro grupo de casos - erro sobre a natureza do ato sexual - pode ser aplicado o § 174c StGB27.

No que diz respeito ao segundo grupo de casos - erro sobre a identidade do autor -, não há um tipo penal correspondente no direito penal alemão, de modo que a conduta se torna impunível.

A despeito do terceiro grupo de casos - engano sobre o estado corporal do autor - é punível a conduta do agente no caso de ser ele portador do vírus HIV e omite esse estado, praticando o crime de lesão

Verbraucherschutz, BT-Drs. 18/9097, S.23). Assim também HOVEN, Elisa; WEIGEND, Thomas. Op. cit., p. 158.

${ }^{25}$ Assim também HOVEN, Elisa; WEIGEND, Thomas. Op. cit., p. 158.

${ }^{26}$ Assim também HOVEN, Elisa; WEIGEND, Thomas. Op. cit., p. 158.

${ }^{27}$ (1) "Wer sexuelle Handlungen an einer Person, die ihm wegen einer geistigen oder seelischen Krankheit oder Behinderung einschließlich einer Suchtkrankheit oder wegen einer körperlichen Krankheit oder Behinderung zur Beratung, Behandlung oder Betreuung anvertraut ist, unter Mißbrauch des Beratungs-, Behandlungs- oder Betreuungsverhältnisses vornimmt oder an sich von ihr vornehmen läßt, wird mit Freiheitsstrafe von drei Monaten bis zu fünf Jahren bestraft“. 
corporal $^{28}$. Enganos sobre a utilização de meios contraceptivos ou até mesmo a capacidade de procriação não são puníveis no Direito penal alemão, além de também não resultar em uma punição no âmbito patrimonial por falta de disposição legal ${ }^{29}$.

Por fim, no que se refere ao quarto grupo de casos - enganos sobre características, motivos ou intenções do autor - não há que se falar em punição no âmbito do Direito penal alemão vigente, a não ser que um outro bem jurídico que não seja a autodeterminação sexual seja lesionado. Por exemplo: é crime o cliente da prostituta que utiliza dos serviços dela, mas a engana sobre a vontade de querer efetuar o pagamento $^{30}$.

Já o modelo de consentimento brasileiro - Nur Ja heißt Ja determinaria a invalidação da manifestação da vontade da pessoa em erro, o que demonstra uma aparente desproporcionalidade. Noutras palavras, qualquer atitude que permita uma distorção ainda que mínima da realidade consistiria em um vício de vontade capaz de, ante a ausência do conhecimento pleno da realidade, invalidar o ato de acordo (Einverständnis) emanado pela pessoa induzida a erro. Tal situação traz um potencial risco de tratamento penal inadequado a condutas que não violem $\mathrm{o}$ bem jurídico liberdade $d a$ autodeterminação sexual.

28223 StGB: (1) "Wer eine andere Person körperlich mißhandelt oder an der Gesundheit schädigt, wird mit Freiheitsstrafe bis zu fünf Jahren oder mit Geldstrafe bestraft". Esse delito-base é aceito nos casos de infecção por meio do vírus HIV. No entanto, a jurisprudência alemã ((BGHSt, 36, S. 1 (9)) vem considerando a aplicação de um outro tipo penal a esse caso, qual seja, a do § 224, (I), 5 do StGB (lesão corporal grave): (1) “Wer die Körperverletzung: (...) 5. mittels einer das Leben gefährdenden Behandlung".

${ }^{29}$ HOVEN, Elisa; WEIGEND, Thomas. Op. cit., p.159.

${ }^{30}$ Idem, ibidem, p.159. 


\section{Conclusão}

Constatou-se que a discussão em torno da liberdade da autodeterminação sexual foi desaguada em razão da incongruência entre os crimes patrimoniais e sexuais. De um lado, tínhamos, por exemplo, o crime de roubo, podendo ser praticado mediante violência ou grave ameaça, e o crime de estelionato, podendo ser praticado mediante o engano para obter vantagem indevida. No âmbito dos crimes sexuais, tínhamos o crime de estupro, praticado mediante violência ou grave ameaça, no entanto, sem a figura correspondente do estelionato previsto nos crimes patrimoniais.

Portanto, o direito penal alemão no ano de 2016, por força da convenção de Istambul, viu-se obrigada a modificar o seu tipo penal, de forma a ampliá-lo. Nessa tentativa não ficou muito claro o sentido e alcance dele. Com o fim de resolver esse impasse foram colocados em debate dois modelos, quais sejam: o modelo do Nein heißt Nein e Nur Ja heißt Ja.

Fora visto que adoção de um ou de outro modelo de consentimento tem um impacto muito grande. De um lado, vimos que o modelo adotado no direito penal alemão não tem o condão de punir quaisquer condutas elencadas nos grupos de casos. Do outro lado, vimos que no direito penal brasileiro é possível a punição de quaisquer condutas. Desse modo, evidencia-se dois extremos, um que ocasiona uma punição exagerada e outro que ocasiona uma não punição.

Ao fim desta pesquisa acreditamos que o modelo adotado pela Alemanha é mais garantista, de modo que ele deveria ser o adotado no sistema jurídico-brasileiro, embora pudesse no futuro ser melhor elaborado. Assim, sugerimos no âmbito do Direito penal nacional uma alteração legislativa, ou seja, propomos uma solução de lege ferenda. 
Além disso, pensamos que poderíamos fundir dois grupos de casos apresentados por Hoven e Weigend. Não vemos a necessidade de termos um grupo de casos referente ao engano sobre a natureza do ato sexual, pois tal categoria poderia ser incluída no engano sobre características, motivos e intenções do agente.

\section{Referências}

BEZJAK, Garonne. Reformüberlegungen für ein neues Sexualstrafrecht. In: ZSTW;130(2):303-339, 2018.

BLUME, Lara; WEGNER, Kilian. Reform des §177 StGB? - Zur Vereinbarkeit des deutschen Sexualstrafrechts mit Art. 36 der Istanbul Konvention. In: Online Zeitschrift für Höchstrichterliche Rechtsprechung zum Strafrecht, 2014.

EL-GHAZY, Mohamad. Der neue Straftatbestand des sexuellen Übergriffs nach $§ 177$ Abs. 1 StGB n.F. In: ZIS 3/2017.

HÖRNLE, Tatjana. Menschenrechtliche Verpflichtungen aus der Istanbul-Konvention: Ein Gutachten zur Reform des $\S 177$ StGB, Berlin, 2015.

- Zeitschrift für die gesamte Strafrechtswissenschaft mit Auslandsrundschau. Band 127, Heft 4, Berlin 2016.

HOVEN, Elisa; WEIGEND, Thomas. Zur Strafbarkeit von Täuschungen im Sexualstrafrecht. In: KriPoZ, 3, 2018. 
JOECKS, Wolfgang; Miebach, Klaus. Münchener Kommentar zum Strafgesetzbuch. Band 3: § 80-184j, C.H.BECK, München, 2017.

Lackner; Kühl. Strafgesetzbuch. Kommentar: 29. Auflage, C.H.BECK, München, 2018.

R v McNally [2013] EWCA Crim 1051; [2014] Q.B. 593 (CA (CrimDiv)).

R v Dica [2004] EWCA Crim 1103; R v Konzani [2005] EWCA Crim 706.

STICK, Brigitte. Zweierlei Recht für zweierlei Geschlecht: Wertungswidersprüche im Geschlechterverhältnis am Beispiel des Sexualstrafrechts. In: ZStW 103 (1991) Heft l, Tübingen.

WALTER, Tonio. Feministische Kriminalpolitik?, in: ZSTW;129(2):492-512, 2017.

WOLTERS, Gereon, In: SK-StGB: Systematischer Kommentar zum Strafgesetzbuch: Band IV, § 174-241a StGB, 9. Auflage, Köln, 2017. 